\title{
Interacionismo simbólico e a possibilidade para o cuidar interativo em enfermagem
}

\author{
SYMBOLIC INTERACIONISM AND THE POSSIBILITY TO THE INTERACTIVE CARE IN NURSING \\ INTERACCIONISMO SIMBÓLICO Y LA POSIBILIDAD PARAEL CUIDAR \\ INTERACTIVO DE LA ENFERMERÍA
}

Consuelo Helena Aires de Freitas Lopes ${ }^{1}$, Maria Salete Bessa Jorge ${ }^{2}$

\section{RESUMO}

O estudo reflexivo e teórico, apresenta os pressupostos básicos do Interacionismo Simbólico, que trata o significado como conceito central da teoria, em que a partir da interação entre as pessoas, as ações são construídas. Procura mostrar a afinidade da enfermagem com essa teoria ao buscar possibilidades para o cuidar interativo seja no âmbito do ensino, prática e pesquisa.

\section{DESCRITORES}

Teoria de enfermagem. Cuidados de enfermagem.

Ensino.

Humanismo

\begin{abstract}
This reflexive and theoretical study presents the basic presuppositions of Symbolic Interactionism, which deals with the signification as the theory's central concept, in which the actions are constructed through the interactions among people. It aims to show the affinity of Nursing with that theory by looking for possibilities for interactive care in teaching, in the practice and in research.
\end{abstract}

\section{KEY WORDS}

Nursing theory.

Nursing care.

Teaching.

Humanism.

\section{RESUMEN}

Este estudio reflexivo y teórico presenta los principios básicos del Interaccionismo Simbólico, que trata del significado como concepto central de la teoría, en que las acciones son construidas a partir de la interacción entre las personas. Procura mostrar la afinidad de la enfermería con esta teoría cuando busca posibilidades para el cuidar interactivo, sea en el ámbito de la enseñanza como en el de la práctica y de la investigación.

\section{DESCRIPTORES}

Teoría de enfermería.

Atención de enfermería.

Enseñanza.

Humanismo.
1 Professora Adjunto do Curso de Graduação em Enfermagem na Universidade Estadual do Ceará/UECE. Doutora em Enfermagem pela Universidade Federal do Ceará/UFC. consueloaires@yahoo.com.br

2 Professora Titular do Mestrado Acadêmico em Saúde Pública da Universidade Estadual do Ceará/UECE e do Programa de Doutorado em Enfermagem da UFC. Doutora em Enfermagem pela Escola de Enfermagem de Ribeirão Preto/Escola de Enfermagem/USP. masabejo@zaz.com.br 
Consuelo H. A. de F. Lopes Maria Salete Bessa Jorge

\footnotetext{
(a) A etnometodologia estuda e analisa as atividades cotidianas dos membros de uma comu nidade ou organização procurando descobrir a forma como esses grupos as tornam visíveis, racionais e reportáveis, ou seja, como as consideram válidas, uma vez que o reflexo sobre o fenômeno é uma característica singular da ação(6)
}

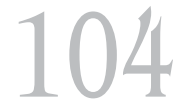

Rev Esc Enferm USP 2005; 39(1):103-8.

\section{A TEORIA E A ENFERMAGEM}

O Interacionismo Simbólico tem sido utilizado com sucesso na Enfermagem por se tratar de uma teoria em que o significado é o conceito central, onde as ações individuais e coletivas são construídas a partir da interação entre as pessoas, que definindo situações agem no contexto social que pertencem.

Um estudo acerca da pesquisa qualitativa em Enfermagem $^{(1)}$, evidenciou a interação simbólica preocupando-se com os aspectos internos experimentais do comportamento humano, isto é, a forma como as pessoas definem eventos ou realidade, e como agem em relação às suas crenças.

Reitera-se os achados anteriores em outro estudo que avalia a perspectiva do Interacionismo Simbólico interpretativo como método significativo para pesquisadores e profissionais de saúde interessados em juízos de valor do fenômeno estudado $^{(2)}$.

Em pesquisas de Enfermagem observamos que a aplicação da teoria interacionista, tanto no ensino e prática, buscam ampliar conhecimentos na construção de ações e estratégias voltadas para um relacionamento interativo e humanizado entre pessoas.

A aplicação dessa teoria na compreensão da trajetória do estudante universitário, inclusive os de enfermagem, demonstrou que os estudantes vivem no mundo de objetos significativos, sendo estes socialmente construídos, os significados surgindo da interação social ${ }^{(3)}$. O aluno universitário não necessita somente do conhecimento teórico disciplinar, mas de um relacionamento humanizado na construção do conhecimento acerca da formação do ser pessoa, para que o mesmo possa construir atitudes interativas ao lidar com pessoas possibilitando exercer sua profissão plenamente.

Outro estudo realizado junto a mulheres mastectomizadas, utilizando o Interacionismo Simbólico no cuidado de Enfermagem, identificou as ações realizadas por essas mulheres e compreendeu os significados atribuídos pelas mesmas $^{(4)}$. Explica que, na perspectiva interacionista, o significado que a pessoa atribui a uma situação vivenciada surge da interação e da interpretação que se faz daquela situação, podendo ser a enfermeira uma mediadora junto ao cliente e família na busca de facilitar tal significação através do ato de reflexão, além de um cuidado mais qualificado.
O objetivo deste estudo consiste em refletir a integração da teoria na prática do cuidado mediante a evolução científica da Enfermagem, vendo como possibilidade para o cuidar interativo o exercício do Interacionismo Simbólico, no âmbito do ensino e prática.

Apresentamos as premissas e conceitos básicos do Interacionismo Simbólico, com vistas a compreensão da teoria que trata da interação social das pessoas, dos sentimentos e atitudes construídas a partir dos significados atribuídos pelas pessoas.

\section{PRESSUPOSTOS BÁSICOS DA TEORIA}

O Interacionismo Simbólico mostra respeito pela natureza da vida e da conduta do grupo humano, estando na vida grupal a condição essencial para a consciência, mundo de objetos e construção de atitudes ${ }^{(5)}$; é princípio que o comportamento humano é autodirigido e observável, no sentido simbólico e interacional, permitindo o ser humano planejar e dirigir suas ações em relação aos outros e conferir significado aos objetos que ele utiliza para realizar seus planos ${ }^{(6)}$.

É uma perspectiva da Psicologia Social, sendo esta uma ciência social que retrata a ação do ser humano na relação com o mundo, focaliza a natureza da interação, a dinâmica social entre as pessoas $^{(7)}$. É a mais ampla perspectiva sobre o papel da comunicação em sociedade ${ }^{(8)}$ e pode ser compreendida como uma vertente da etnometodologia ${ }^{(a)}$.

O Interacionismo Simbólico teve origem no fim do século XIX com destaque para George Herbert Mead, que como homem da ciência, foi influenciado pelo pragmatismo filosófico e behaviorismo $^{(7)}$. Reune estudos de figuras americanas notáveis, como do próprio George Herbert Mead, John Dewey, W. I. Thomas, Robert E. Park, William James, Charles Horton Cooley, Florian Znaniecki, James Mark Baldwin, Robert Redfield, e Louis Wirth ${ }^{(5)}$.

Mead foi professor da Escola de Chicago no período de 1893 a 1931. Fundamenta a teoria na descrição do comportamento humano, cujo dado principal é o ato social, concebido como comportamento "externo" observável e também como atividade "encoberta" no ato. Ele se opunha à teoria de John B. Watson, seguidor da Escola de Iowa, que reduz o comportamento humano aos mecanismos ao nível infra-humano, cuja dimen- 
são social é vista apenas como influente sobre o indivíduo ${ }^{(6)}$.

Mead escreveu artigos, mas a sua influência foi mais pelas publicações de leituras e notas por seus estudantes, bem como pela interpretação de seus trabalhos por vários sociólogos, especialmente por Herbert Blumer ${ }^{(7)}$. As suas obras foram compiladas e editadas após a sua morte em 1931, sendo a mais conhecida Mind, Self and Society, editada em $1934^{(8)}$.

Em 1937, Herbert Blumer atribuiu à sua abordagem teórico-metodológica a expressão "interacionismo simbólico"(8), pela convicção de que a ciência empírica deveria ser respeitada, por ser o mundo empírico o objeto de estudo e, para ser estudado, seria necessária uma metodologia. Assim, iniciou escritos que representavam com clareza os pressupostos básicos da abordagem interacionista, tendo a preocupação de criar uma metodologia, pois os manuscritos de Mead não possuíam uma sistemática teórica.

Blumer manteve-se fiel ao pensamento de George Herbert Mead, a partir dos escritos e até publicações de aulas, palestras, notas e manuscritos fragmentados sobre a teoria, que explorou não somente a complexa relação entre sociedade e indivíduo, como também a gênese do self, desenvolvimento de símbolos significantes e processo de comportamento da mente (Haguette, 1992) ${ }^{(6)}$.

Iniciou escritos que representavam com clareza os pressupostos da abordagem interacionista ${ }^{(5)}$. Portanto, o Interacionismo Simbólico conta com a última análise de três premissas simples criadas por Blumer:

a) os seres humanos agem em relação às coisas, tomando por base o significado que as coisas tem para ele;

b) o significado de tais coisas, às vezes, surge de uma interação social que a pessoa tem com seus iguais;

c) esses significados são manipulados e modificados através de um processo interpretativo, usado pela pessoa para lidar com as coisas que ele encontra.

O Interacionismo Simbólico, fundamentado nessas premissas, é levado a desenvolver um esquema analítico da sociedade e das condutas humanas, que envolve idéias básicas relacionadas a grupos humanos ou sociedades, interação social, objetos, o ser humano como ator, a ação humana e as interconexões das linhas de ação ${ }^{(6)}$.
A teoria desenvolve uma micro-análise por estudar as interações interindividuais, a negociação individual e reação do outro, levando às atividades interpretativas, determinadas pela situação e interação das pessoas.

Para a compreensão da perspectiva teórica, fazse necessária a compreensão de conceitos pertinentes à sua interação, tais como, mente, self, coisas, símbolos, linguagem, sociedade, autointeração, ação humana e atividade grupal, descritos da seguinte forma.

A natureza do próprio ser humano concebe o self sendo social, através da interação com os significados do outro, na relação com o mundo, para permitir o seu controle, direção e manipulação da própria vida. É formado pelo Eu e Mim, sendo o Eu a resposta para as atitudes do outro, o lado impulsivo, espontâneo e que não age porque interage simbolicamente com si próprio. O Mim é a organização das atitudes ${ }^{(7)}$, é o outro generalizado, composto de padrões organizados, consistentes, compartilhados com outros ${ }^{(8)}$.

A mente é a ação simbólica para o self e, surge da interação com outros, dependendo de ambos os selves e símbolos ${ }^{(7)}$.

As coisas a que Blumer se refere, incluem o que o ser humano pode observar em seu mundo físico e, conforme o significado que essas coisas têm para o ser humano, suas ações são dirigidas a essas coisas; portanto, é tomado como base o significado das mesmas ${ }^{(8)}$.

Os símbolos são o que vemos e, como interpretamos, e o nosso mundo é de símbolos, a nossa realidade é simbólica; é através da interação simbólica que atribuímos os significados e desenvolvemos a realidade que agimos ${ }^{(7)}$. Na terminologia meadiana, um gesto compartilhado é um símbolo significante. Em suma, a sociedade nasce nos símbolos significantes do grupo $^{(8)}$.

A linguagem é composta por instrumentos usados por indivíduos para ordenar a experiência. É empregada para discriminar, generalizar, fazer sempre a distinção no ambiente. Assim, o mundo é literalmente dividido por significados que usamos através da linguagem ${ }^{(7)}$. A linguagem surge e modela o comportamento ${ }^{(8)}$.

Os interacionistas definem a sociedade como constituída de indivíduos que interagem uns com os outros; quando as atividades dos membros ocorrem como resposta de um ao outro, ou em relação ao outro $^{(8)}$.

O significado surge da interação de duas pessoas, ou seja, o significado que uma coisa tem para
Interacionismo simbólico e a possibilidade para o cuidar interativo em enfermagem 
Consuelo H. A. de F. Lopes Maria Salete Bessa Jorge uma pessoa cresce da forma pela qual as outras pessoas agem em relação a ele com relação a essa coisa. O significado é formado dentro e através de atividades definidoras das pessoas quando interagem $^{(5)}$.

O processo interpretativo é derivado do contexto da interação social. O que ocorre é que a pessoa escolhe, checa, suspende, reagrupa e transforma o significado à luz da situação como um processo formativo, no qual os significados são usados e revisados como um instrumento para as diretrizes da ação ${ }^{(5)}$. Podemos assim dizer, que o processo interpretativo através da autointeração leva a uma re-significação do vivido, em que os valores individuais interferem no significado que as coisas têm para a pessoa.

A auto-interação, portanto emerge da interação social, em que outras pessoas estão definindo uma pessoa para si. Para Mead, isso acontece quando a pessoa se vê pelo lado de fora, colocando-se na posição do outro e se vendo ou agindo em relação a si nessa posição ${ }^{(5)}$.

A ação humana é vista como um resultado formado da auto-interação; é construída através das indicações que a pessoa faz a si e interpretação do que indica para agir. A pessoa identifica que quer estabelecer uma meta, mapeia uma linha de comportamento, observa e interpreta as ações dos outros, dimensiona a sua situação, checase, elabora o que fazer com os outros pontos ${ }^{(5)}$.

$\operatorname{Mead}^{(9)}$ dividiu a ação do ser humano em quatro estágios: impulso, percepção, manipulação e consumação, e definiu que a essência da ação é causada pela decisão tomada pela pessoa ativamente através desses estágios como segmentos da ação. As regras e normas para as ações dos sujeitos se manifestam através da negociação de significados, de sanções, de hierarquias e das próprias normas sociais ${ }^{(8)}$.

A atividade grupal baseia-se no comportamento cooperativo que surge através de cada pessoa em perceber a intenção dos outros e construir a sua resposta baseada naquela intenção, pois o comportamento não é uma resposta direta às intenções dos outros, que são transmitidas através de gestos tornados simbólicos, passíveis de interpretação ${ }^{(5)}$.

A pessoa que responde, organiza sua resposta tomando por base o que os gestos significam. A pessoa que apresenta os gestos como indicações do que está planejando fazer, tomando por base aquilo que quer que o respondente faça ou compreenda. Com efeito, o gesto tem significado tanto para a pessoa que faz como para a quem é dirigido. A interação simbólica, que envolve o processo de interpretação da ação, procura compreender o significado da ação de cada outro $^{(5)}$.

A ênfase na concepção interacionista de significado é sobre a interpretação consciente; as coisas passam a ter significado para a pessoa quando esta as consideram conscientemente, reflete e pensa sobre o objeto, ou o interpreta, e isso se processa numa interação interna da pessoa, pois o ator seleciona, confere, suspende, reagrupa e transforma os significados à luz da situação em que está colocado e da direção que imprimiu à sua ação. Assim sendo, a interpretação é um processo formativo e não uma aplicação sistemática de significado já estabelecido ${ }^{(6,8)}$.

Ainda, o Interacionismo Simbólico sob a perspectiva Interpretativa, indo além da compreensão dos significados e construção de atitudes das pessoas a partir das relações interpessoais, configura-se por referencial teórico-metodológico que possibilita a avaliação de resultados em saúde.

Este intuito tem estado centrado na realização de pesquisas avaliativas para verificar a qualidade na oferta de serviços, quando parte-se do entendimento de que tal serviço tem estreita relação com aspectos interpessoais; como também questões sobre a mudança de comportamento relacionado ao conhecimento e adesão a determinadas situações ligadas a mudança no estilo de vida das pessoas ${ }^{(2)}$.

\section{A ENFERMAGEM E O CUIDAR INTERATIVO}

Teoristas de Enfermagem têm ampliado significados do cuidar/cuidado para uma perspectiva humanística e interacionista da enfermeira cuidando de pessoas, buscando superar o cuidado praticado sob uma visão de ordem mecanicista e reducionista sob a compreensão de que este contexto é conseqüente a formação de profissionais dentro dos modelos tradicionais em saúde e educação.

Em toda a sua trajetória, a Enfermagem tem interpretado o cuidado como existência profissional, mas observa-se o cuidado de Enfermagem ainda deficiente e distante de uma concepção holística. Percebe-se ainda no cuidar empírico, a presença do modelo médico - clínico, do pensa- 
mento tecnocrático, que entende a doença e não o homem, considerando-a como processo biológico do indivíduo.

No entanto, percebe-se que para uma Enfermagem melhor, essas atitudes diante do modelo tradicional não devem ser abandonadas, e sim repensadas em uma dimensão maior; dimensão esta que entende as pessoas como ser-no-mundo, possuidoras de liberdade de ação, capazes de interagir na tomada de decisões.

Destacamos aqui, a Teoria da Enfermagem Humanista ${ }^{(10)}$, em que o significado do cuidar constitui-se no ato humano em si, sendo uma forma de diálogo humano e fenômeno vivido no cotidiano da Enfermagem, que mostra a enfermeira, no cuidar, como ser singular, que considera o modo como o cliente vive o seu mundo.

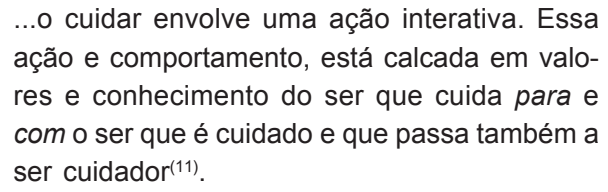

Para o cuidado acontecer na sua plenitude, a enfermeira deve expressar conhecimento e experiência das atividades técnicas, na prestação da informação e na educação ao paciente e sua família. Deve conjugar expressões de interesse, sensibilidade, respeito, demonstradas por palavras, tom de voz, postura, gestos e toques ${ }^{(11)}$. Assim, expressase o cuidar como arte e ciência.

Oportuno ainda enfatizar a importância do compromisso de qualquer enfermeira, de qualquer área de atuação profissional, de procurar humanizar-se, estabelecendo uma relação mais criativa e amorosa consigo mesma e com os outros, descobrindo o compromisso com a valorização e o apoio ao self de quem estiver mais perto de si, ou seja, cuidando-se também ${ }^{(12)}$.

Assim sendo, uma vez que a Enfermagem está em contínuo relacionamento humano, necessitando do processo interativo para o exercício pleno de seu ofício, acreditamos na clara aproximação com o interacionismo simbólico. No entanto, mediante a compreensão de que a Enfermagem tem buscado expressar-se com um fazer cientifico humanizado, em que o cuidar humano têm se evidenciado como o propósito da profissão, pretende-se aqui apresentar como ponto reflexivo do presente estudo, questões que traduzem as diferenças e conflitos entre a teoria e prática na Enfermagem.

\section{INTEGRAÇÃO DA TEORIA COM A PRÁTICA DA ENFERMAGEM: PONTOS DE REFLEXÃO}

A Enfermagem como disciplina da saúde, ainda se expressa como mister puramente tecnicista $\mathrm{e}$ acrítico, em que se percebe o cuidado ainda voltado para os aspectos biológicos do homem, sem interação com os aspectos emocionais, sociais e culturais. O modelo biomédico tem a concepção da separação de mente e corpo, limitando-se a compreender os mecanismos biológicos, não adotando uma abordagem holística em saúde ${ }^{(13)}$.

Essa constatação faz-nos entender que a Enfermagem, além das influências recebidas na sua origem e durante a história no seu desenvolvimento como ofício de saúde, com conseqüências enfrentadas até os dias atuais, continua a contabilizar, como ocorre com as demais profissões, influências da evolução das Ciências nas áreas da saúde e educação.

Isso leva-nos a mencionar as influências das políticas sociais na educação e saúde para a formação de seus profissionais. Na sua trajetória inicial, a Enfermagem acolheu influxos da escola tradicional, desde o ensino informal, às primeiras tentativas de profissionalização, sendo consolidada esta pedagogia nas primeiras escolas de Enfermagem. A partir dos anos 1950, é alvo da ação da escola tecnicista, nomeadamente no período pós 1964, quando houve a formação de grande número de escolas de Enfermagem, cujo enfoque funcionalista estava centrado na assistência hospitalar. Apenas mais recentemente, a partir dos anos 1980, a Enfermagem inspira-se na pedagogia da escola crítica, através de reflexões, eventos científicos e mudança curricular no ensino ${ }^{(14-15)}$.

O currículo da Enfermagem foi iniciado com um enfoque generalista e comunitário, sendo adaptado às políticas de saúde emergentes e ao modelo de privatização dos serviços de saúde, resultando na valorização da especialização precoce e domínio da tecnologia, nem sempre encontrada na nossa realidade ${ }^{(16)}$. Atualmente a Enfermagem sofre a crise de identidade, evidenciada pela reflexão critica sobre o seu papel, em face das necessidades reais da sociedade, o que gerou discussões e ensejou um movimento de reforma curricular ${ }^{(14)}$.

A perspectiva, portanto, de refletir o cuidar de Enfermagem humanizado deve-se a compreensão deste contexto, como conseqüência de questões pertencentes ao atual sistema de saúde, associadas às questões inerentes à nossa profissão, que
Interacionismo simbólico e a possibilidade para o cuidar interativo em enfermagem 
Consuelo H. A. de F. Lopes Maria Salete Bessa Jorge traduzem as influências sóciopolítica e econômica, na evolução das ciências. São esses pontos que fazem a atenção à saúde deficiente, em especial pela presença e vigência dos modelos tradicionais da saúde e da educação dos profissionais (modelo biomédico, escola tradicional, escola tecnicista), sendo presente o relacionamento vertical, a comunicação unilateral, a autonomia do processo na saúde e na educação, uma prática na saúde e educação desvinculada da realidade social, favorecendo o distanciamento entre teoria e prática.

As concepções progressistas na saúde e educação entendem os processos como não sendo autônomos, e sim comprometidos com a realidade social do homem, havendo interdependência. $\mathrm{Na}$ educação, as vertentes pedagógicas libertadora, libertária e crítico-social dos conteúdos, defendem a educação vinculada ao social, partindo da análise das realidades sociais e buscando a transformação da sociedade ${ }^{(15)}$. Na saúde, esta é vista nas dimensões físicas, psicológicas e sociais, decorrentes da complexa interação entre suas várias facetas, refletindo o sistema social e cultural, sendo a doença apenas uma das numerosas manifestações de um desequilíbrio básico do organismo ${ }^{(13)}$.

\section{REFERÊNCIAS}

(1) Chenitz WC, Swanson JM. Qualitative research in nursing. California: Addson - Wesley; 1986.

(2) Andrade SMO, Tanaka OY. A avaliação de resultados em saúde sob a perspectiva do interacionismo interpretativo. Rev IMIP 2000; 14(1):7-12.

(3) Jorge MSB. Indo em busca de seu Plano de Vida: a trajetória do estudante universitário. Florianópolis: Papa Livro; 1997.

(4) Silva RM, Mamede MV. Conviver com a mastectomia. Fortaleza: UFC; 1998.

(5) Blumer, H. Symbolic interacionism perspective and method. Califórnia: Prentice-Hall; 1969.

(6) Haguette TMF. Metodologias qualitativas na sociologia. 3. ed. Petrópolis: Vozes; 1992.

(7) Charon M. Symbolic interacionism: an introduction, an interpretation, an integration. Califórnia: Prentice-Hall; 1989.

(8) Littlejohn SW. Fundamentos teóricos da comunicação humana. Rio de Janeiro: Zahar; 1992.

(9) Mead GH. Mind, self and society: from the standpoint of a social behaviorist. Chicago: University of Chicago Press; 1972.
A Enfermagem está inserida nesse processo, evoluindo junto das ciências contemporâneas. Apesar do desafio, tem buscado se desenvolver de forma contextualizada com a realidade da sociedade no âmbito da pesquisa, ensino e assistência.

Tem buscado nas demais ciências fundamentos que propiciem o cuidar humanizado, mas contextualizado com o mundo de vidas das pessoas.

Compreendemos a Enfermagem buscando na Sociologia, Psicologia, Educação, Antropologia, entre outras ciências, vertentes para o disciplinamento do saber. Assim, situamos o Interacionismo Simbólico, cujo movimento da teoria nasceu em clássicos da sociologia e psicologia social, como teoria que tem aproximação com a Enfermagem, dada a sua perspectiva de compreensão dos aspectos subjetivos das pessoas.

Entendemos a Enfermagem como profissão do cuidado da vida - agindo com profissionais de outras disciplinas, sendo que o cuidar requer interação transpessoal entre profissionais, com o cliente e família. Assim, é que acreditamos na fundamentação da Teoria do Interacionismo Simbólico como ponto reflexivo e possibilidade para o cuidado interativo.
Correspondência p/: Rua Rosa Cordeiro, 420

Bloco 12, Apto 401.

- Bairro Edson Queiroz

CEP. 60481-245

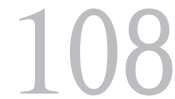

Rev Esc Enferm USP 2005; 39(1):103-8.
(10) Paterson JG, Zderad LT. Humanistic nursing. New York: National League for Nursing; 1988.

(11) Waldow VR. Cuidado humano: o resgate necessário. Porto Alegre: Sagra Luzzato; 1998.

(12) Randuns V. Cuidando e se cuidando: fortalecendo o self do cliente oncológico e o self da enfermeira. Goiânia: AB; 1997.

(13) Capra, F. O ponto de mutação. Trad. de A. Cabral. 22. ed. São Paulo: Cultrix; 1999.

(14) Unicovsky MAR. A formação profisssional do enfermeiro: reflexão, ação e estratégia. In: Saupe $\mathrm{R}$, organizador. Educação em enfermagem. Da realidade construída à possibilidade em construção. Florianópolis: Ed. da UFSC; 1998. p. 219-41.

(15) Nietsche EA. As teorias da educação e o ensino de enfermagem no Brasil. In: Saupe R, organizador. Educação em enfermagem. Da realidade construída à possibilidade em construção. Florianópolis: Ed. da UFSC; 1998. p. 119-61.

(16) Saupe R. Ação e reflexão na formação do enfermeiro através dos tempos. In.: Saupe R, organizador. Educação em enfermagem. Da realidade construída à possibilidade em construção. Florianópolis: Ed. da UFSC, 1998. p. 29-73. 